\title{
Hierros antiguos en la Meseta oriental. La Celtiberia olvidada The earliest Iron of the Central Iberian Peninsula. The forgotten Celtiberia
}

\author{
$M^{a}$ Luisa Cerdeño' \\ Marta Chordá ${ }^{2}$
}

Recibido: 08-03-2017

Aceptado: 25-09-2017

\section{Resumen}

En este artículo se presentan los objetos de hierro más antiguos descubiertos en yacimientos celtibéricos, que con frecuencia pasan desapercibidos en el debate sobre las antiguas producciones férricas peninsulares. Son hallazgos relevantes porque están bien contextualizados desde el punto de vista estratigráfico y cronológico. Su presencia indica que los habitantes de aquellas regiones, rica en minas de hierro, adoptaron desde el inicio de la Edad del Hierro el uso de este metal y posiblemente su técnica de fabricación.

Palabras clave: Metalurgia del hierro. Península Ibérica. Cultura celtibérica. Primera Edad del Hierro.

\begin{abstract}
In this paper it is being showed the oldest iron elements in Celtiberian area, because frecuentley they are forgotten among the discussions of the old Peninsula iron productions. Those are relevant finding because they are well contextualized under stratigraphic and chrononological point of view. All this demonstrates that the people of this geographical area, with important iron mines, used this metal objects and probably they manufactured them from the Early Iron Age.
\end{abstract}

Keywords: Iron metallurgy. Celtiberian Culture. Iberian Peninsula. Early Iron Age.

\section{INTRODUCCIÓN ${ }^{3}$}

El conocimiento de la metalurgia del hierro y la fabricación de cerámicas a torno son dos de las tecnologías que caracterizan bien a las sociedades de la Edad del Hierro y los investigadores han prestado atención recurrente al momento en que ambas se adoptaron en los territorios peninsulares y al impacto socio-económico que pudieron suponer en el desarrollo cultural de sus habitantes.

Las evidencias disponibles en el registro para documentar los primeros hierros son menos abundantes que

1 Departamento de Prehistoria. Universidad Complutense de Madrid.mluisac@ucm.es

2 Centro de Estudios Celtibéricos de Segeda. marta_chorda@hotmail.com en el caso de la cerámica y quizás por ello se sigue buscando ampliar la información que sobre aquellos procesos tenemos. En el intento de los arqueólogos por reconstruir los diferentes pasos realizados hasta conseguir las piezas que ahora encontramos, observamos que se conocen mejor los dos extremos de aquella cadena operativa, si situamos en el primero de ellos a los minerales de los que proceden, puesto que hay filones férricos que pudieron ser explotados en las etapas protohistóricas y, en el extremo opuesto, el resultado final en forma de adornos, armas o herramientas, siendo mucho más desconocidos los escalones intermedios

3 Este trabajo se ha realizado dentro del Proyecto del Ministerio de Economía y Competitividad (HAR201568032-P): "La Serranía Celtibérica y Segeda. El Patrimonio Histórico como motor de Desarrollo Rural" 
de la extracción, fundición y forja. Esta es la razón por la que desde hace mucho tiempo conozcamos los diferentes tipos existentes ya que los estudios tipo-cronológicos tuvieron mayor tradición que otro tipo de enfoques y, por ello también, pensamos que esas imprescindibles clasificaciones deben ser revisadas y actualizadas para que las bases de datos que seguimos utilizando sean metodológicamente más correctas.

En el estudio de la introducción del nuevo metal en la Península, la preocupación principal de los estudiosos se centró sobre todo en averiguar las rutas de llegada de la nueva tecnología metálica hasta este extremo suroccidental de Europa y, aunque una revisión profunda de este tema excede el propósito y el espacio de este artículo, lo mencionamos únicamente para enmarcar el caso celtibérico, comprobando que siempre se aceptó que esta innovación tecnológica llegó de fuera, al igual que el mencionado torno de alfarero, variando hacia donde se decantaron las conclusiones.

Mayoritariamente se propuso como vía principal de llegada la colonización fenicia, incluso durante la fase precolonial, siendo emblemáticos yacimientos como el Tesoro de Villena, Trayamar o Almuñecar (por ejemplo Aubet 1987, 264. Almagro-Gorbea 1993. Ruíz-Gálvez 1993 y 2012. Torres 2002. Celestino et alii 2008). También se propuso la vía transpirenaica y algunos autores afirmaron que el hierro se introdujo por el Noreste, vía continental, resaltando las similitudes entre el sur de Francia y Cataluña (por ej. Pons 1986-87, 252 y 2003, 122. Rafel, 1991, 132), aunque a veces se reducía esta influencia al ámbito del Ampurdán y se creyó que también la nueva técnica había llegado al cuadrante nororiental de la mano de los colonizadores mediterráneos (por ej. Ruíz-Zapatero 1992. López-Cachero 2007. López-Cachero et alii 2012. Graells 2010) puesto que en la Cataluña interior y el Bajo Aragón hay hierros asociados a cerámicas de importación.

Se siguen publicando trabajos referidos a diferentes regiones de Portugal y España, tanto de las zonas occidentales (por ejemplo Sousa 2016. Vilaça 2006. Mederos 2008. Peña 1992. Álvarez-Sanchís 2000) como de las meridionales (Ruiz-Gálvez 1995. Torres 2017), del sureste y la costa mediterránea (GonzálezPrats 1992 y 2014. Lorrio, 2008. Rovira 2010. Jover et alii 2016) o de la Meseta sur (Ruiz-Zapatero 2007). Y también trabajos de síntesis que abarcan toda la Península, en los que inexplicablemente queda excluido el territorio celtibérico (Álvarez-Sanchís et alii 2016) a pesar de que abarcó una amplia extensión, en sus límites se ubican algunos de los filones de hierro más importantes y en los últimos años se han encontrado datos que muestran un temprano uso del hierro en la Primera Edad del Hierro. Aceptando la línea difusionista generalizada, parece que la entrada de la nueva metalurgia hacia los territorios meseteños se realizaría con facilidad desde el valle medio del Ebro, al limitar con las altas tierras de la Meseta oriental y existir diferentes rutas practicables (fig. 1).

La cultura material de los celtíberos, y en especial los objetos metálicos, se conoce bien desde hace ya cien años gracias a los hallazgos realizados por el marqués de Cerralbo durante sus excavaciones en más de una decena de necrópolis y por su posterior conservación en su famosa colección arqueológica. Desde el punto de vista tipológico se valoraron broches, fíbulas y otros muchos adornos de bronce, así como las armas de hierro, siendo estudiadas y clasificadas casi desde el principio (por ej. Cabré 19391940. Cabré y Cabré 1933). Aquella valiosa documentación fue utilizada enseguida en los estudios generales sobre la Hispania céltica, siendo el más relevante el de Bosch Gimpera (1921) a quién le sirvió de base para su periodización, en la que todos esos yacimientos quedaron enmarcados en su tardía fase "posthallstáttica", espacio cronológico que permaneció inamovible mucho tiempo y que sigue siendo difícil variar, a pesar de que en aquellas colecciones apenas se pueden identificar asociaciones de objetos ni su posición estratigráfica y, por ello, no deberían servir para intentar fijar cronologías absolutas.

Consecuentemente, la actividad científica de las últimas décadas se ha centrado en la búsqueda y excavación sistemática de nuevos poblados y necrópolis que permitieran ampliar y mejorar la base de datos pero, sobre todo, que proporcionaran aquello de lo que carecíamos los investigadores y que eran conjuntos cerrados, asociaciones seguras, estratigrafías contrastadas y cronologías absolutas que las viejas colecciones nunca tuvieron y que están ayudando a la actualización de muchos datos y a revisar muchos tópicos que entonces se formaron. Y lo estamos intentando varios equipos de investigación que trabajamos en diferentes "núcleos arqueológicos" del territorio celtibérico como el del Bajo Jalón-Jiloca en las provincias de Zaragoza y Teruel, el del Jalón Medio-Alto Tajo donde destacan los descubrimientos de la comarca de Molina de Aragón, el área de MedinaceliSigüenza-Atienza en el norte de Guadalajara y sur de Soria y el núcleo de Numancia con centro en el emblemático yacimiento.

Los datos que se han ido descubriendo están permitiendo revisar antiguas tipologías ya que constituyen una imprescindible herramienta en el trabajo arqueológico pero, en general, nunca son definitivas e inamovibles. La aparición de nuevas asociaciones de objetos y algunas fechas absolutas permiten reordenar los elementos materiales y articular la evolu- 
ción de los mismos porque disponer de un referente temporal adecuado es fundamental para comprender los acontecimientos que los generaron pues, como dicen algunos autores, es necesario contar con un criterio independiente para ubicar las manifestaciones arqueológicas en el contexto de las prácticas sociales donde estuvieron involucradas (Castro et al., 1996: 3). El caso de los hierros celtibéricos es un ejemplo de ello porque durante mucho tiempo se pensó que solo habían hecho su aparición ya avanzada la Edad del Hierro y ahora sabemos que su utilización, y seguramente su fabricación, se remontan bastante tiempo atrás.

Esa larga experiencia de los celtíberos permitió el desarrollo de una técnica metalúrgica de gran perfección que mucho tiempo después alcanzó merecida fama, reflejada en numerosos textos greco-romanos. Las fuentes escritas resultan valiosas porque mencionan la riqueza minera del territorio, sus eficaces armas y sus tácticas de guerra y, aunque son tardías y se alejan mucho en el tiempo del tema que ahora tratamos, revelan una larga tradición comprobada también en otros muchos aspectos culturales. Diodoro Sículo describió con detalle las armas y el modo de fabricarlas: “(...) Sus espadas tienen doble filo $y$ están fabricadas con excelente hierro, también tienen puñales de un palmo de longitud. Siguen una práctica especial de fabricación de sus armas pues entierran laminas de hierro y las dejan así, hasta que con el curso del tiempo el oxido se ha comido las partes más débiles quedando solo las más resistentes (...). El arma fabricada de esta forma descrita corta todo lo que pueda encontrar en su camino, pues no hay escudo, casco o hueso que pueda resistir el golpe dada la extraordinaria calidad del hierro ..." (V, 33 y ss). Las referencias a la calidad del hierro de estas regiones quedaron también plasmadas en muchos otros textos, como en uno de los epigramas de Marcial, donde dice que su querida Bilbilis está "orgullosa de su oro y de su hierro" (Mangas y Myro 2003, 233), en Plutarco cuando comenta "Pues como los celtíberos templan el hierro, cuando después de haberlo metido bajo tierra, le quitan la mayoría de sus impurezas" (Ibidem, 241) o en otros autores como Justino o Plinio. (fig. 1)

\section{LA DOCUMENTACIÓN DISPONIBLE}

El inicio de la metalurgia del hierro en Celtiberia hace ya tiempo que se sitúa en la Primera Edad del Hierro pues son numerosos los elementos bien contextualizados en necrópolis y poblados, al formar parte de asociaciones significativas desde el punto de vista tipocronológico. Nos fijamos principalmente en los yacimientos donde se han realizado trabajos en los últimos años y describimos sucintamente los objetos que se pueden adscribir al período Celtibérico Antiguo y que tienen una especial significación cultural.

\subsection{Los objetos de hierro más relevantes}

Armas. Siempre han sido los elementos de hierro más valorados por los investigadores puesto que proporcionan información tanto sobre el nivel tecnológico de su fabricantes, como sobre el estatus social y económico de quienes las utilizaron, y por ello han sido objeto de estudios pormenorizados desde hace tiempo (por ej. Quesada 1991 y 1997. Lorrio 1994). Tampoco es el objetivo de estas líneas hacer una revisión de las tipologías en uso, sino de subrayar el interés de algunos hallazgos recientes que demuestran su temprana manufactura.

Uno de los primeros hallazgos de armas encuadrables en contextos más antiguos que los tradicionales fue el de la necrópolis de Sigüenza I (Guadalajara) donde aparecieron puntas de lanza, regatones y numerosos cuchillos asociados a las estructuras tumulares y a cerámica exclusivamente a mano (fig. 2). No se encontraron espadas que, en cambio, si estaban representadas en la fase siguiente, Sigüenza II, ya en la Segunda Edad del Hierro (Cerdeño y Pérez Ynestrosa 1993, 54 y ss). Estas primeras puntas de lanza, largas y estrechas, procedentes de cuatro tumbas, fueron incluidas como representativas de los primeros tipos IA y IIA de la panoplia celtibérica propuesta en los trabajos reseñados (Quesada 1991, 941 y 1997, 626. Lorrio 1994) y otras en el tipo IIA, muy relacionado con el anterior. Pero una pieza que nos parece destacable es el cuchillo de dorso recto y punta descendente aparecido en la tumba 31 de Herrería III junto a cuatro fíbulas navarro-aquitanas (Fig. 3 y 5) pues coincide con uno de los modelos de cuchillos más representados en las necrópolis del sur de Francia y de Cataluña, a los que se considera de lujo al estar frecuentemente acompañados de otros tipos de fíbulas antiguas, y que han sido objeto de atención pormenorizada en un reciente trabajo que los fecha desde el siglo VIII a. C. y a lo largo de la Primera Edad del Hierro, (Zamora 2015, 21-22), cronología aceptada para el momento de transición entre el Bronce Final y la Edad del Hierro (por ej. López Cachero y Rovira, 2012, 41-43).

En general, la necrópolis de Herrería III (Guadalajara), con fechas absolutas antiguas (fig. 6) es ilustrativa porque las armas de hierro formaban parte de los ajuares de 34 tumbas (22\%), normalmente aparecían varias juntas y/o acompañadas de otros objetos, destacando las puntas de lanza, los regatones y los 22 cuchillos (14,3\%). Tampoco había espadas, pues el mal estado de conservación de cinco posibles casos impide una clara identificación (Cerdeño y Sagardoy 2007, 134). 


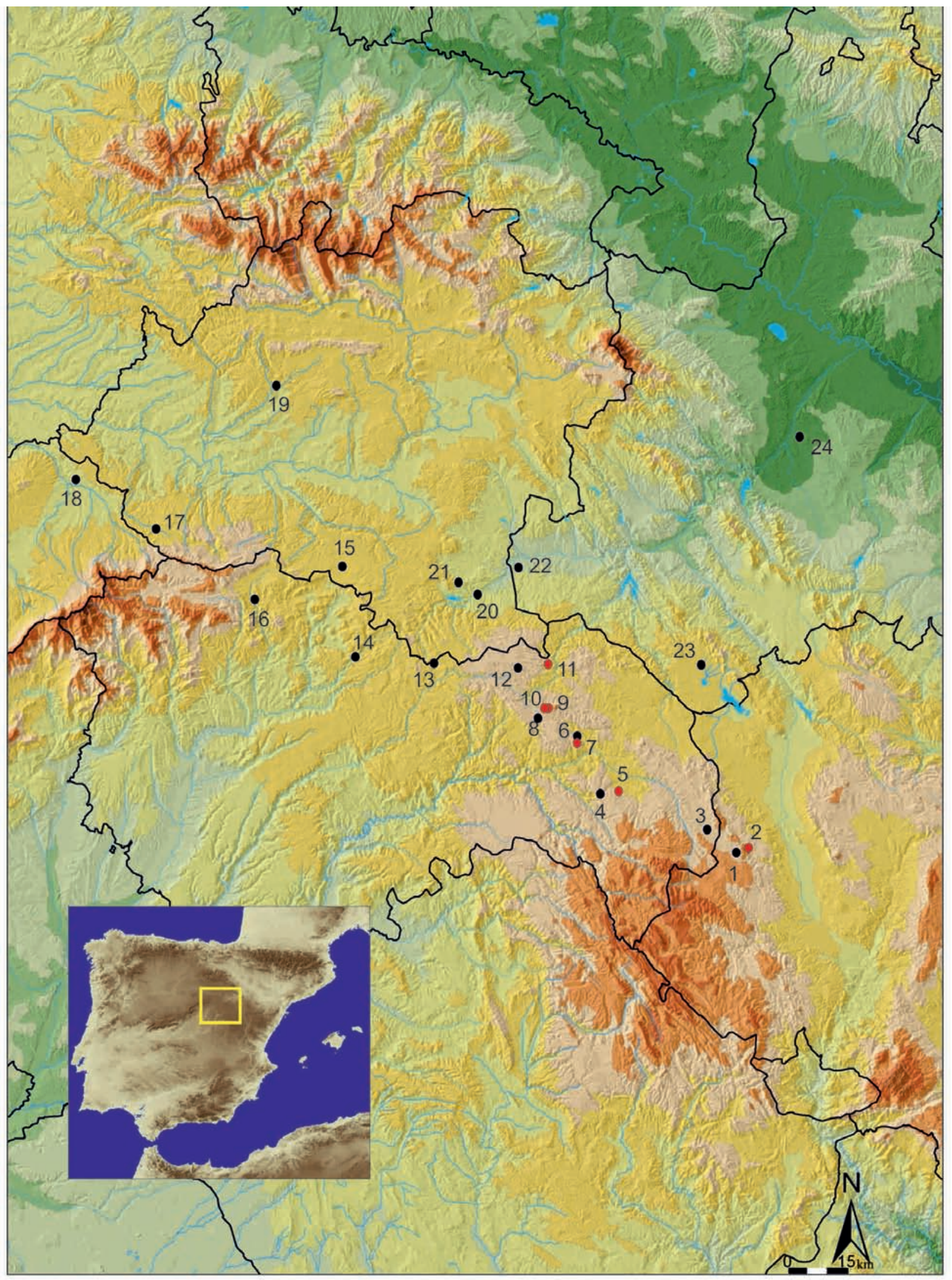

Fig. 1.- Localización de los yacimientos celtibéricos estudiados en el texto: 1. El Cuarto, Griegos; 2. Montón de Tierra, Griegos; 3. Puente de la Sierra, Checa; 4. Chera; 5. La Coronilla, Chera; 6. Herrería III; 7. El Ceremeño, Herrería; 8. La Cerrada de los Santos, Aragoncillo; 9. El Palomar, Aragoncillo;

10. El Turmielo, Aragoncillo; 11. La Torre, Codes; 12. Navafría, Clares; 13. Aguilar de Anguita; 14. Sigüenza; 15. Alpanseque; 16. Atienza; 17. Carratiermes; 18. La Dehesa de Ayllón; 19. La Mercadera; 20. El Inchidero; 21. Almaluez; 22. Arcóbriga; 23. La Umbría; 24. Cabezo de Ballesteros. 


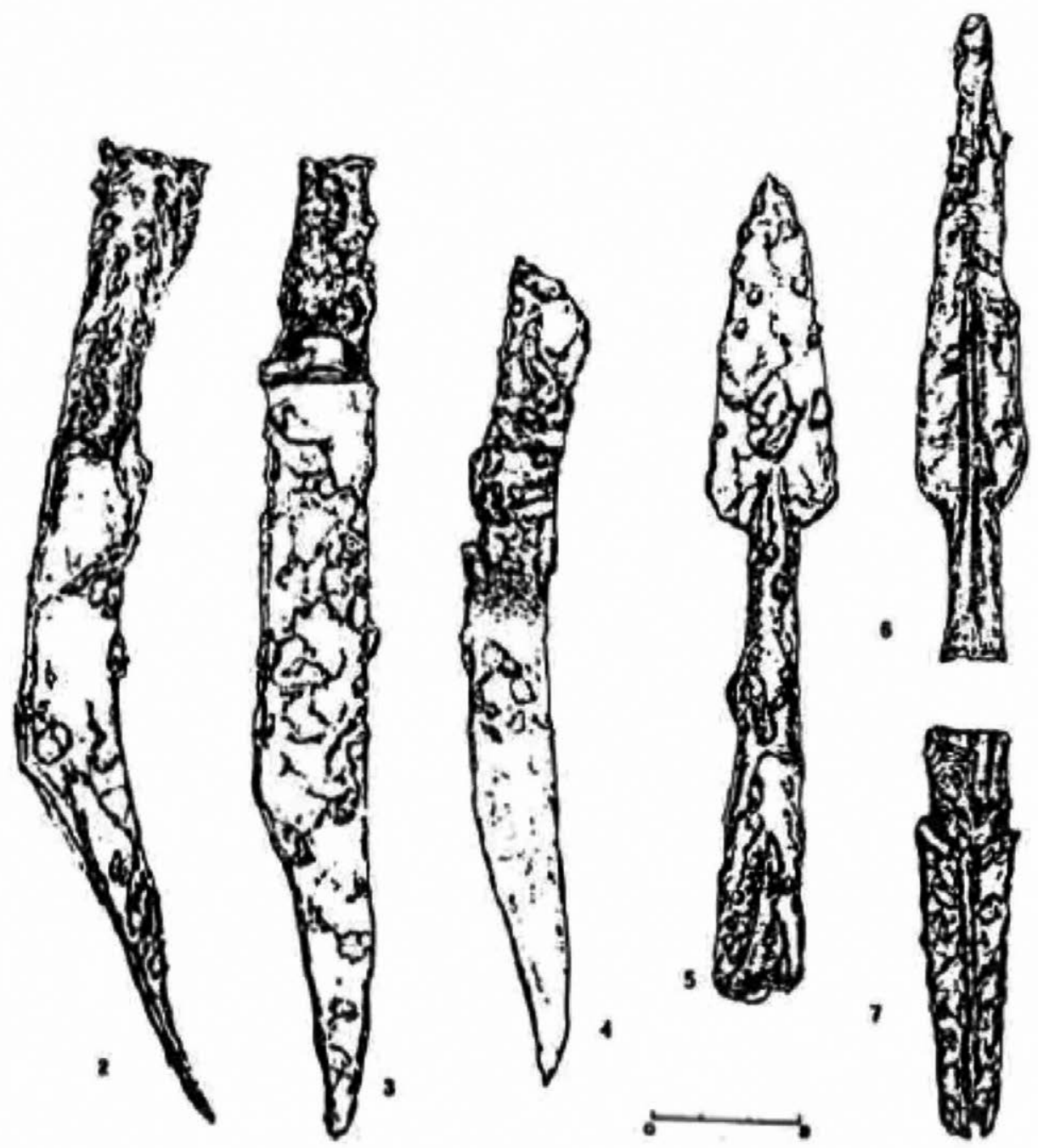

Fig. 2.- Armas de hierro de la tumba 15 de Sigüenza I (Cerdeño y Pérez de Inestrosa, 1993, 24).

Fíbulas navarro-aquitanas. Constituyen uno de los elementos más significativos del nuevo registro porque en la Meseta solamente se conocían hasta ahora ejemplares sueltos entre las colecciones antiguas, a los que nunca se había prestado demasiada atención. Su denominación hace referencia al foco dónde fueron descubiertas y sistematizadas por primera vez (Maluquer 1953. Mohen 1974) pero, una vez revisadas las necrópolis celtibéricas, se comprobó que estaban representadas en 19 de ellas, por lo que no se las puede considerar piezas marginales, sino más abundantes que en otros lugares cercanos (Cerdeño y Chordá 2004, 164).

Las similitudes tipológicas de muchos elementos materiales celtibéricos, incluidas estas fíbulas, con los de la ribera navarra es evidente y también con la Francia meridional donde está uno de los focos principales de estas fíbulas, aunque con ciertas variantes (Escudé-Guillet 1998, 235), confirmando la relación entre estos territorios. Pero esa relación fue bidireccional y se está replanteando la forma y momento, no siendo necesariamente más antiguos los modelos franceses (Constantin y Chordá 2014, 227).

La asociación de estas fíbulas con otros materiales antiguos ha quedado bien demostrada en la necrópolis de Herrería III, cuyas 153 tumbas quedan incluidas en la Primera Edad del Hierro sin demasiadas dudas, tras su rigurosa excavación y estudio (fig. 5) y el interés es mayor porque no ha aparecido un ejemplar aislado, sino que se han recuperado nueve fíbulas de este modelo formando parte de diferentes ajuares. El conjunto más selecto es el de la tumba 31 donde se encontraron cuatro fíbulas de hierro haciendo juego con un pequeño cuchillo de dorso recto y punta curvada del mismo metal (fig. 3), cuyo mango estaba adornado con los mismos discos de bronce que rematan los resortes de las fíbulas. Como decíamos antes, este tipo de cuchillo está muy bien documentado en las necrópolis 
del sur de Francia y en las catalanas desde finales del Bronce Final, siendo un buen ejemplo la de Can PiteuCan Roqueta (López Cahero, 2007, 110 . Zamora, 2015, 21). Aparte de este conjunto, recordemos que en Herrería III han aparecido otros modelos de fíbulas en tumbas adyacentes, contemporáneas pues, cuya cronología de la Primera Edad del Hierro hasta ahora nadie discutía: una de codo con pivote, nueve de bucle, dos de El Acebuchal y cuatro de doble resorte, tipos todos ellos muy representativos (fig. 5). Estas asociaciones de objetos quedan también fijadas por las dataciones radicoarbónicas obtenidas, que se comentan en el siguiente apartado.

De las otras dieciocho necrópolis con este modelo de fíbula comentamos las de reciente excavación, como la de Sigüenza I donde apareció un ejemplar junto a puntas de lanza y regatones procedentes de una tumba destruida, pero de similares características a las demás (Cerdeño y Pérez de Inestrosa 1993, 38). En Molina-Chera hay una fíbula recogida en la superficie y podría incluirse en el conjunto de la zona excavada (Cerdeño et alii 1981, 56). En Carratiermes I hay un ejemplar en una sepultura de la que no se da mayor información (Argente et alii 2001, 96). En la necrópolis de Griegos se recuperó una fíbula durante la prime- ra excavación que se ha revisado recientemente junto al resto de los materiales y la fecha radiocarbónica (Chordá 2008, 13), (figs. 3 y 6). De las necrópolis descubiertas por Cerralbo comentamos las de Almaluez y Alpanseque, en el sur de Soria, porque sus ejemplares están recogidos en el famoso corpus de las fíbulas de la Meseta Oriental (Argente, 1994, 175 y 197) y hemos intentado reconstruir sus contextos originales contrastado la revisión que se hizo de los materiales de la primera (Domínguez, 1982) y con el catálogo fotográfico de Juan Cabré (Blánquez y Rodríguez, 2004), aunque es una tarea casi imposible.

Más cercanas al valle del Ebro, recordamos las necrópolis de La Umbría y Cabezo de Ballesteros, ambas en la provincia de Zaragoza, pues los ajuares de que formaban parte estas fíbulas se relacionaron con los ejemplares navarros y franceses, fechándose en la Primera Edad del Hierro (fig. 6). En Cabezo de Ballesteros propusieron una cronología del siglo VII a. C. (Pérez-Casas 1990, 115), mientras que en La Umbría (Aranda 1990,101), a pesar de su contexto, se valoraron como un elemento indicativo de una continuidad temporal hacia fases más recientes, según la antigua adscripción "posthallstática" del ejemplar de Griegos (Almagro 1942).

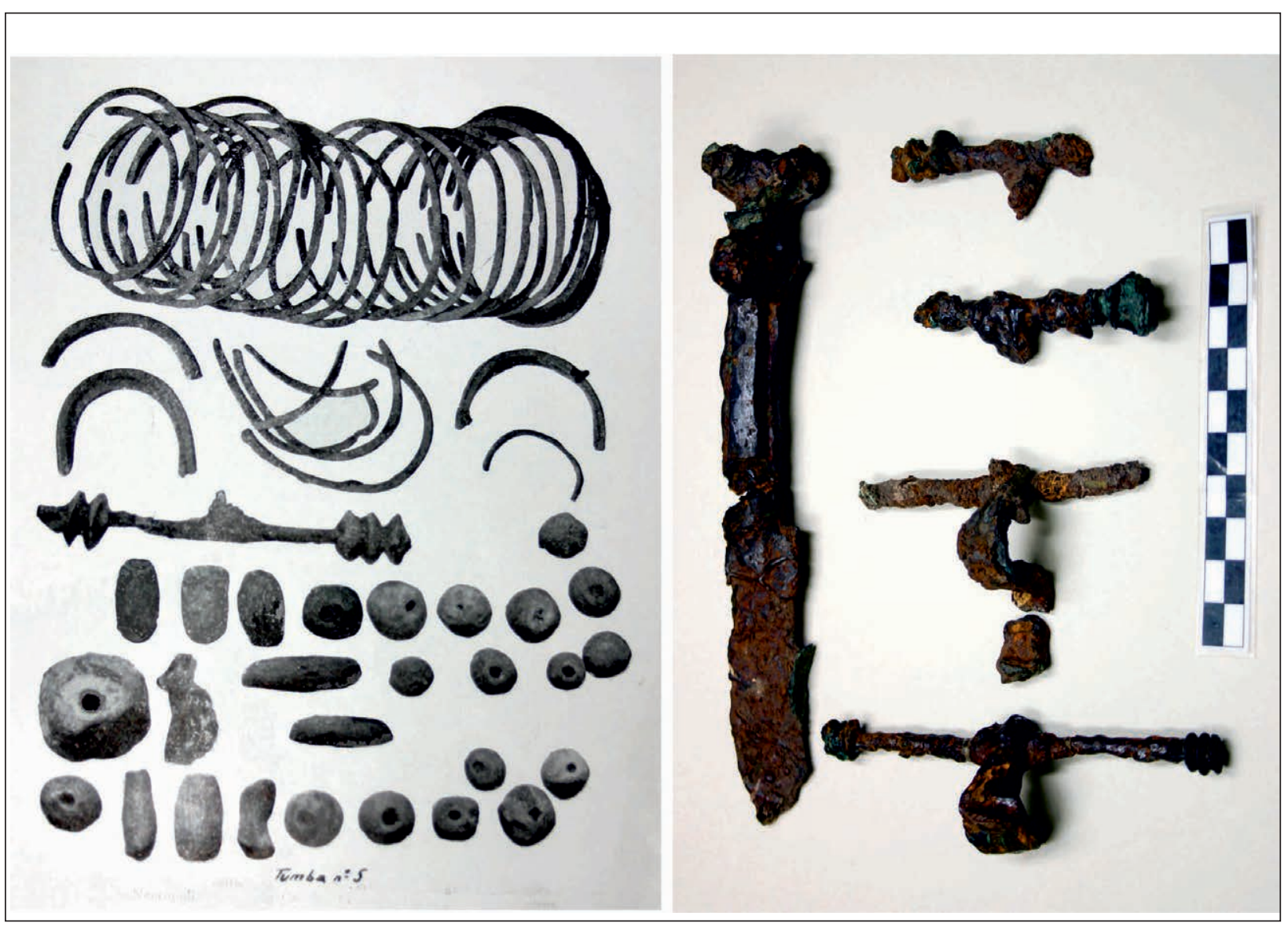

Fig. 3.- A. Tumba 5 de la necrópolis de Griegos (Almagro Basch, 1942). B. Conjunto de cuchillo de hierro de dorso recto y fíbulas navarro-aquitanas encontradas en la tumba 31 de Herrería III. 
Soportes. Los soportes de hierro, denominados "elementos de tocado" o "tocados femeninos" y al margen de su discutida funcionalidad (Lorrio, 1997, 233. Cerdeño y Sagardoy, 2007, 139), nos parecen objetos interesantes porque, aparte de los conservados en las antiguas colecciones, han aparecido recientemente en contextos del Celtibérico Antiguo y ello permite revisar todo el conjunto y trazar su mapa de dispersión que parece seguir un eje sureste-noroeste desde Teruel a Soria, con una cronología descendente (Chordá y Pérez-Dios, 2014, 405).

Los 11 ejemplares de Herrería III son significativos al formar parte de los ajuares de diez sepulturas, en dos de ellas como pieza única y en otras acompañadas de cerámicas a mano, broches de cinturón, fíbulas de bucle, pulseras, lanzas o un cuchillo de hierro, este último caso en la tumba 47, que también ha proporcio-

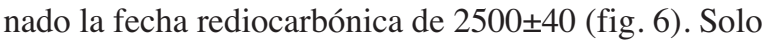
en dos de las tumbas se identificaron los restos óseos como femeninos (Cerdeño y Sagardoy 2007, 138). En la cercana necrópolis de la Cerrada de los Santos I se encontraron dos ejemplares en tumbas adscritas al Celtibérico Antiguo (Arenas 1999, 51 y ss) (fig. 4), acompañados de pulseras, brazaletes, espiraliformes y finas placas de bronce. En la necrópolis de MolinaChera se encontró un soporte de hierro, así como una fíbula navarro-aquitana revueltos, fuera del área en que trabajamos, pero cabe pensar que procedían del mismo nivel tumular que excavamos y que, por diferentes elementos, situamos en el período Celtibérico Antiguo (Cerdeño et al. 1981, 64 y fig. 13)

Más al sur de la comarca molinesa, la necrópolis de Puente de la Sierra en Checa ha proporcionado otro ejemplar en la tumba 138 en la que también había brazaletes, finas láminas de bronce, láminas articuladas y una fíbula naviforme (Martínez Naranjo y de la Torre 2014, 59) que al principio fecharon en el siglo V a. C. por su paralelismo con la de Clares, a pesar de ser una necrópolis descubierta por Cerralbo y descontextualizada debido a los avatares sufridos a lo largo del tiempo (Malpesa 1993, 17 y ss), pero que ahora consideran de la fase más antigua porque, según comunicación oral, se ha obtenido una fecha absoluta alta aún no publicada.

En el otro extremo del mencionado eje de dispersión, han aparecido recientemente tres nuevos soportes en la necrópolis de El Inchidero (Soria) en tumbas adscritas a la primera fase datada entre los siglos VI-V a. C. (Arlegui, 2012, 181 y 2014, 384). Esta cronología es algo más reciente que la anteriormente mencionada y permite observar una interesante secuencia espaciotemporal en el uso de estas piezas, que ofrecen fechas más modernas a medida que se desplazan hacia el Duero y el Jalón medio, donde se ubican las necrópolñis de Viñas de Portuguí (Fuentes, 2000), Quintanas de Gormaz (Taracena, 1941, 138) y Arcóbriga (Lorrio y
Sánchez de Prado, 2009) cuyos soportes se podrían revisar desde esta nueva perspectiva. Quedan una serie de hallazgos en puntos geográficos intermedios, como las necrópolis de Almaluez, Alpanseque, Aguilar de Anguita y Clares, todas ellas excavadas por Cerralbo, de las que se conservan, además de los soportes, objetos semejantes a los documentados en Herrería III o en Griegos. La revisión pormenorizada de estos antiguos cementerios está siendo abordada por una de nosotras en otro trabajo todavía inédito.

\section{Pulseras y aros de hierro}

Destacamos la existencia de otras piezas de adorno en estos ajuares meseteños, algunas asociadas directamente a las fíbulas antes mencionadas. En Herrería III se recuperó una pulsera de hierro abierta y rematada en sus extremos por sendos discos (fig. 5), a la que consideramos un objeto de prestigio por su morfología, por su nueva materia prima y porque apareció en la tumba 142 en unión de una fíbula navarroaquitana (Cerdeño y Sagardoy 2007, 99 y 137). Las pulseras de hierro, al igual que algunos modelos de bronce, no son frecuentes en las necrópolis celtibéricas y parecen exclusivas de esta fase antigua, como ocurre en las necrópolis del sur de Aquitania, por ejemplo en la de Ibos o en el túmulo de LamarquePontacq, fechados en el Bonce Final IIIb, donde estas pulseras representan los primeros hierros de la zona (Escudé-Quillet 2000, 134. Mohen 1980). En la necrópolis de La Dehesa de Ayllón (Segovia) también se recuperaron dos pulseras y dos arandelas de hierro que, por su asociación a fíbulas de doble resorte, puntas de lanza y cuchillos, el autor del estudio considera adscritos a la fase antigua (Barrio 2006, 67 y 74).

En el ámbito celtibérico no se conocen más piezas similares pero si en algunas necrópolis de la ribera navarra, como La Atalaya de Cortes. En sus ajuares se recuperaron muchas pulseras, mayoritariamente de bronce pero también algunas de hierro de sección maciza circular con remate de sencillos botoncitos (Castiella 2005, 175, 186, fig. 101) lo que nos parece interesante ya que en dicha necrópolis abundaban las fíbulas navarro-aquitanas, las puntas de lanza y los cuchillos de hoja curva, siendo las armas elementos minoritarios en esta y otras necrópolis cercanas (Castiella y Tajadura 2001, 216). Como otros autores han comentado, la metalurgia del hierro en estos territorios navarros estuvo muy ligada a los recursos mineros del Sistema Ibérico, especialmente los del Moncayo (Faro y Unzu 2006, 159). Las pulseras y anillas no debieron tener el mismo simbolismo que los torques, algunos fabricados en hierro (Brun 2002, 47 ), pero si debieron ser objetos de lujo al tratarse de un metal todavía escaso y por tanto con un acceso restringido. 


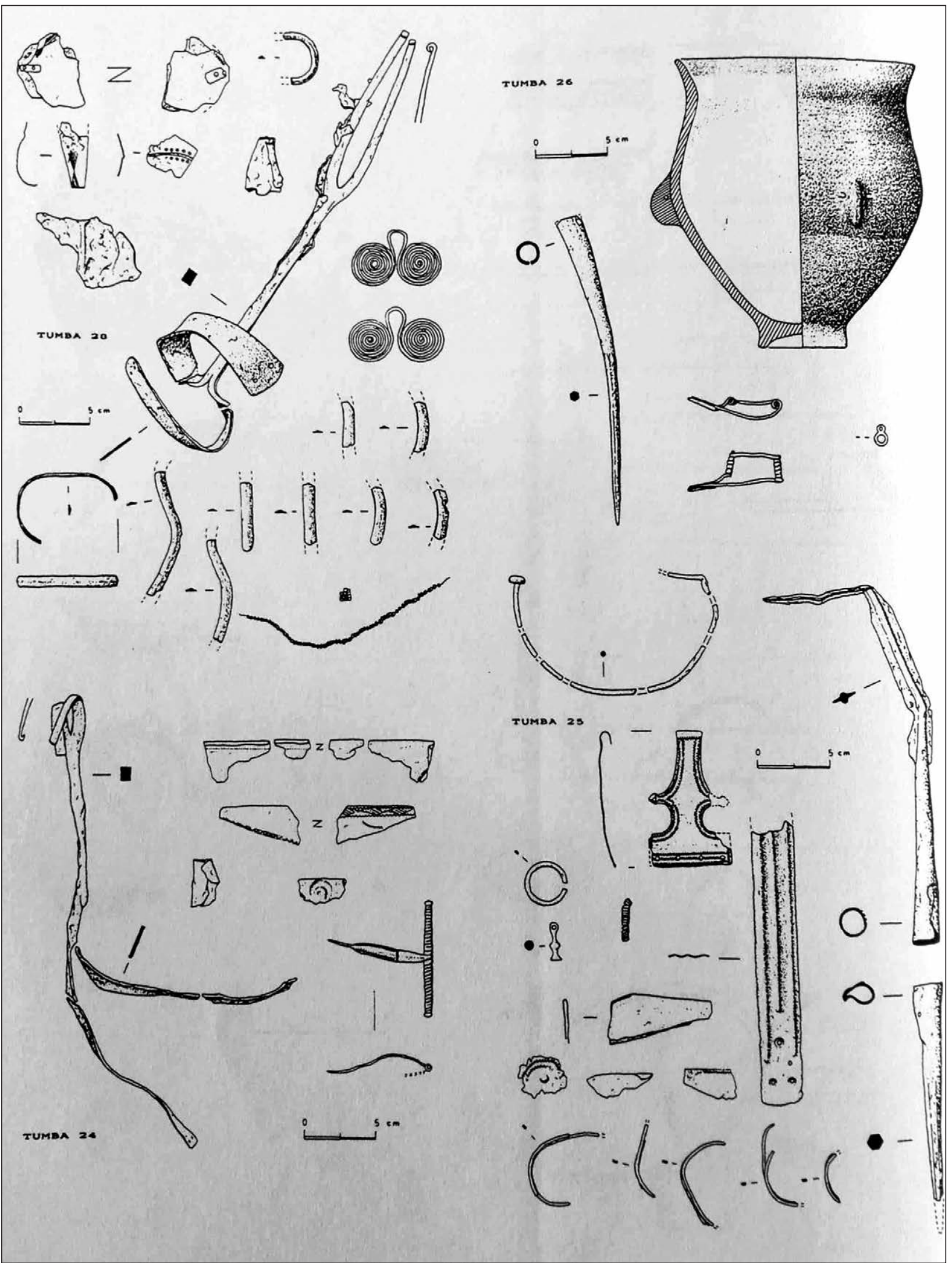

Fig. 4.- Tumbas del nivel antiguo de la necrópolis de la Cerrada de los Santos (Aragoncillo), con soportes de hierro en dos de ellas (Arenas, 1999, 62). 
Hierros indeterminados. En algunos yacimientos se han recuperado fragmentos de hierro que por su mal estado de conservación no pueden incluirse en ningún tipo concreto, aunque su mera presencia en contextos del inicio de la Edad del Hierro los convierte en elementos significativos. Es el caso de los pequeños e indeterminados fragmentos aparecidos en Ceremeño I, uno en el suelo de la vivienda $\mathrm{C}$ y nueve en el suelo de la vivienda H (Cerdeño y Juez 2002, 82) bien estratificados en ese nivel de ocupación y asociados a morillos prismáticos, cerámicas a mano bicónicas, fíbulas de codo con pivote y de tipo Acebuchal o cerámicas a torno del Ibérico Antiguo, además de la fecha de C-14 (fig. 6). Sin embargo, los análisis metalográficos realizados en uno de ellos no han proporcionado demasiada información técnica debido al estado de corrosión (Rovira et alii 2002, 170). También es significativa la lupia de hierro, de varios kilos de peso, encontrada en este mismo yacimiento entre el lienzo de la muralla y la torre suroeste, sobre los carbones y cenizas del nivel de incendio. Aunque no está demasiado clara su adscripción a una u otra ocupación, por su posición se pensó que era un material de desecho de la primera fase. Tanto en este caso como en el de los fragmentos anteriores, son destacables las similitudes estructurales con los hierros analizados en el castro de Castilmontán, en Soria, puesto que se trata de un asentamiento del mismo contexto cultural (Rovira et alii 2002, 175).

En los niveles antiguos del poblado de Vallipón (Teruel), vinculados a la influencia de los Campos de Urnas, se recuperaron numerosas escorias de hierro que parecían demostrar una metalurgia bien desarrollada (Martín Costea y Ruíz-Zapatero 1980) y también resulta interesante el fragmento indeterminado de hierro encontrado durante la prospección del poblado de Las Terraceras I (Teruel) en unión de numerosas cerámicas a mano de tradición de Campos de Urnas y de pesas de telar, que permitieron fechar el conjunto en la Primera Edad del Hierro, en torno al siglo VII a. C. (Ruíz Zapatero y Marín-Costea 1984, 13 y 18). Lo más interesante es que se realizaron análisis metalográficos a esta pieza e indicaron que estaba compuesta fundamentalmente de hierro metálico y que el procedimiento de fabricación había sido bastante elemental (Ibidem, 30).

Fuera del estricto ámbito celtibérico, nos interesa la necrópolis de Arroyo Culebro (Madrid), fechada por diferentes métodos en siglo VIII a. C. a inicios de la I Edad del Hierro, y paralelizada con Herrería III por los autores del estudio. Dicen que en esta fase antigua el hierro era inexistente, excepto por un pequeño fragmento (Baquedano et alii 2016, 215-16) que nosotras, sin embargo, consideramos relevante. La mera presencia de este metal en conjuntos seguros es interesante por su asociación a determinados tipos cerámicos y metálicos que coinciden con otros enclaves que incluimos en este trabajo e indicativos, todos ellos, de que no se trata de casos aislados o descontextualizados, sino que son ejemplo de que la fabricación de objetos de hierro, al principio escasa, era una práctica habitual que se extendió con cierta rapidez.

\section{2. Las fechas radiocarbónicas}

La utilidad metodológica de las fechas absolutas en el estudio de períodos protohistóricos se discutió e incluso se desestimó hace años si las cifras obtenidas no confirmaban las cronologías previamente establecidas (Castro et al., 1996, 35), idea que se acentuó en el caso de las calibraciones. Esta perspectiva ha ido cambiando y son pocos los que renuncian a utilizarlas como método de datación eficaz aunque, con frecuencia, su uso evita la discusión sobre la verdadera teoricidad de los términos en que descansan las interpretaciones históricas antes ofrecidas (Vega, 2002, 128). La base de las periodizaciones descansaba mayoritariamente en la tipología de materiales considerados diagnósticos, aunque muchos de ellos carecieran de un buen contexto estratigráfico.

En el caso de la cultura celtibérica, la obtención de dataciones absolutas en los últimos años ha permitido confirmar aquello que los datos arqueológicos venían apuntando y es que su desarrollo fue un proceso largo que desborda el marco convencional de la Edad del Hierro y remonta sus orígenes a las últimas etapas del Bronce Final y que casi todas las características materiales que la definen estaban presentes desde el inicio de la Edad del Hierro, cuyos límites se han ampliado un siglo más atrás de lo que tradicionalmente se aceptaba (figs. 6 y 7). Se alejan, así, los "siglos oscuros" que impedían conocer sus etapas de formación y se amplian definitivamente aquellas fases posthallstáticas en las que se constriñó todo el proceso celtibérico (Cerdeño y Sagardoy 2007 y 2016). Esto mismo ocurre en los demás ámbitos peninsulares en los que también se han ampliado hacia atrás los límites cronológicos de la Primera Edad del Hierro, que enlaza de manera coherente con el precedente Bronce Final, del que también hay cada vez más dataciones radiocarbónicas. Y nos fijamos especialmente en el sur de Francia, Cataluña y el Bajo Aragón porque desde allí llegaron bastantes influencias que contribuyeron a gestar la entidad cultural que llamamos celtibérica.

Las fechas del castro de El Ceremeño I (ver discusión en Vega, 2002, 126 y ss) y sobre todo las de la necrópolis Herrería III (ver discusión en Vega, 2007, 183) resultaron muy significativas, al igual que la fecha de los niveles inferiores de la Torre de Codes II (Arenas 1999: 70, 199) pues ayudan a perfilar mejor los inicios de la Edad del Hierro en estas regiones meseteñas. Otro caso interesante es el de la necrópolis de Griegos donde, a raíz de la revisión de sus materia- 


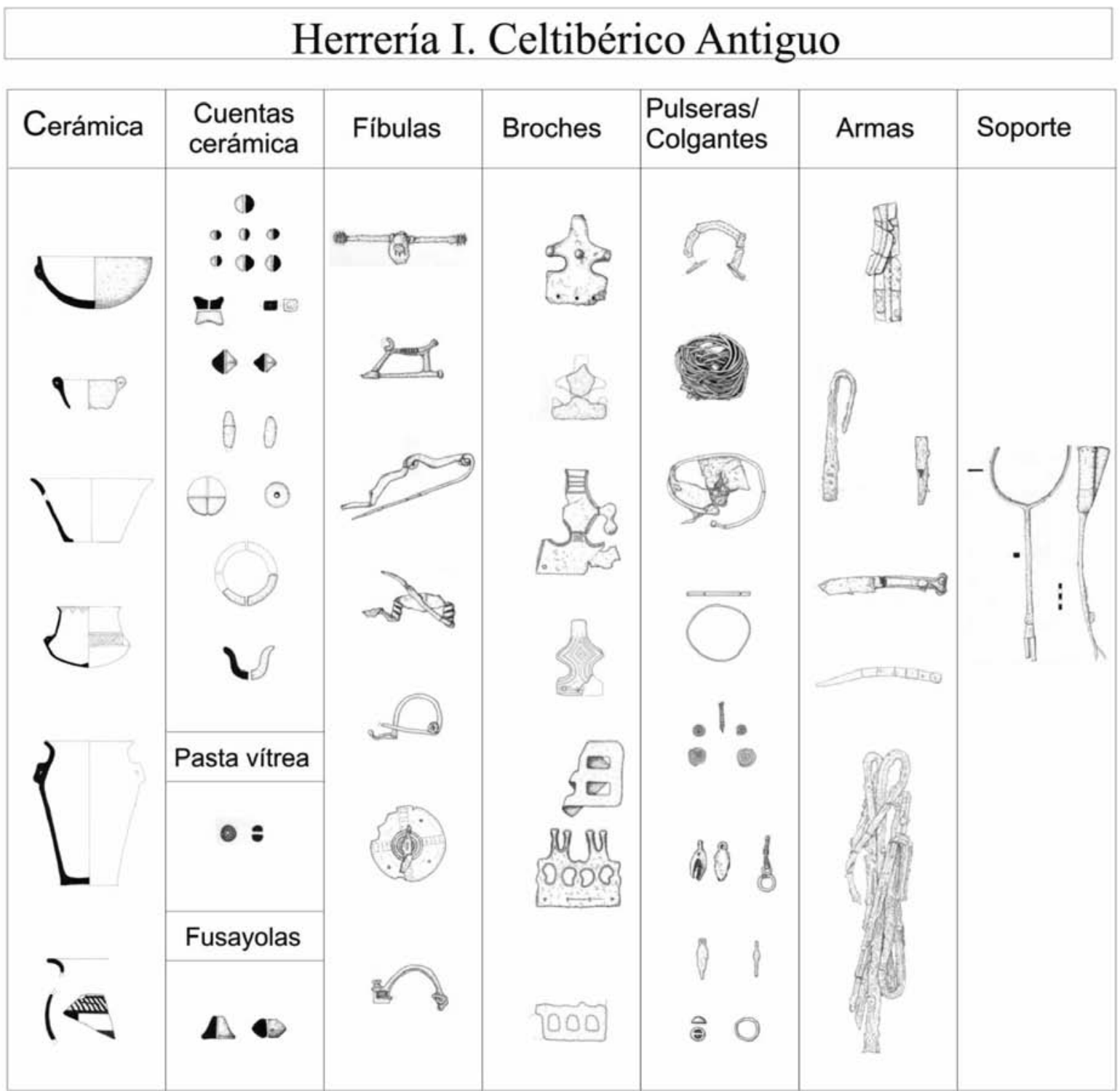

Fig. 5.- Objetos documentados en los ajuares de Herrería III, que muestran interesantes asociaciones y contemporaneidades (Cerdeño y Sagardoy, 2007, 143).

les y de una fecha radiocarbónica de una de sus tumbas, se ha identificado un horizonte del período Celtibérico Antiguo (Chordá 2008), coincidente con la datación obtenida en el cercano El Montón de Tierra (Collado et al., 1991-1992. Chordá et al., 2014, 234.).

Estas fechas de la Primera Edad del Hierro no son todavía muy abundantes pero creemos que no se deben desestimar sin mayores consideraciones porque, además, ocupan una posición intermedia entre las del Bronce Final y el conocido siglo V a. C., perfilándose ya una secuencia ininterrumpida de varios siglos, bien visible en el registro material. En el caso de fechas del Bronce Final, volvemos a mencionar el ejemplo de la necrópolis de Herrería pues las 10 dataciones de la fase I y las 6 de la fase II, entre los años 1100 y 790 a. C., enlazan directamente con las de la fases III y IV, con- firmando la utilización ininterrumpida del mismo lugar funerario durante casi un milenio (Fig. 7). Por el otro extremo resultan de gran interés las dataciones de la necrópolis soriana de El Inchidero (Arlegui, 2014, 382), donde se identifican las fases del Celtibérico Antiguo, Pleno y Tardío. Las correspondientes al período antiguo son algo más recientes que las de la comarca del Alto Tajo y coinciden con la aparición de nuevos elementos, como por ejemplo bocados, que la aproxima a la creciente influencia arévaca a partir del siglo V a. C (Arlegui, 2014, 382). Estas series radiocarbónicas ofrecen fechas consecutivas que corroboran las estratigrafías estudiadas sin entrar en contradicción, siendo fechas concordantes (Quesada, 2012, 425) y van conformando una amplia serie que se perfila hasta el final de la Edad del Hierro. 


\begin{tabular}{|c|c|c|c|c|c|c|}
\hline Yacimiento & Muestra & Edad $C^{14}$ BP & \multicolumn{2}{|c|}{ Rango cal a. C. } & \multirow{2}{*}{\multicolumn{2}{|c|}{$\begin{array}{c}\text { Media ponderada } \\
2555 \pm 28\end{array}$}} \\
\hline \multirow{5}{*}{ 1. Herrería III } & & & (1 sigma) & $(2$ & & \\
\hline & $\begin{array}{l}\text { Beta-210530 } \\
\text { ( T-47 }\end{array}$ & $2500 \pm 40$ & $\begin{array}{l}767-731 \\
691-660\end{array}$ & $\begin{array}{l}\text { S1gma) } \\
790-505\end{array}$ & \multirow{4}{*}{$\begin{array}{l}\text { (1 sigma) } \\
797-756 \\
584-554 \\
606-603\end{array}$} & (2 sigma) \\
\hline & quemada) & & & $462-450$ & & $801-747$ \\
\hline & & & & $441-417$ & & $684-669$ \\
\hline & $\begin{array}{c}\text { Beta-210531 } \\
\text { (T-68 madera } \\
\text { quemada) }\end{array}$ & $2600 \pm 40$ & $814-773$ & $\begin{array}{l}893-877 \\
845-750 \\
687-666 \\
639-593\end{array}$ & & $\begin{array}{l}688-665 \\
644-587\end{array}$ \\
\hline \multirow{3}{*}{ 2. Ceremeño I } & I-16770 & $2380 \pm 200$ & $780-355$ & $907-13 \mathrm{~d}$. & \multicolumn{2}{|c|}{$2466 \pm 74$} \\
\hline & (carbón) & & & C. & \multirow{2}{*}{$\begin{array}{l}(1 \text { sigma) } \\
760-681 \\
667-612\end{array}$} & $\begin{array}{l}\text { (2 sigma) } \\
779-406\end{array}$ \\
\hline & $\begin{array}{l}\text { I-16771 } \\
\text { (carbón) }\end{array}$ & $2480 \pm 80$ & $763-515$ & $781-411$ & & \\
\hline $\begin{array}{l}\text { 3. Torre II de } \\
\text { Codes }\end{array}$ & - & - & \multicolumn{2}{|c|}{669} & \multicolumn{2}{|c|}{ - } \\
\hline 4. Griegos & Beta-246557 & $2540 \pm 50$ & $\begin{array}{l}790-750 \\
690-660 \\
640-590\end{array}$ & $800-520$ & \multicolumn{2}{|c|}{770} \\
\hline \multirow{5}{*}{$\begin{array}{l}\text { 5. Montón de } \\
\text { Tierra }\end{array}$} & GrN- 18.225 & & $\begin{array}{c}1370-1360 \\
1310-810\end{array}$ & $\begin{array}{c}1520-470 \\
440-410\end{array}$ & \multicolumn{2}{|c|}{$890 \pm 220$} \\
\hline & GrN- 18.229 & & $\begin{array}{l}986-960 \\
936-896 \\
876-850\end{array}$ & $996-840$ & \multicolumn{2}{|c|}{$815 \pm 35$} \\
\hline & GrN- 18.277 & & $\begin{array}{l}894-878 \\
864-806\end{array}$ & $902-802$ & \multicolumn{2}{|c|}{$720 \pm 40$} \\
\hline & GrN- 18.228 & & $\begin{array}{c}1260-1230 \\
1220-390\end{array}$ & $1610-60$ & \multicolumn{2}{|c|}{$680 \pm 350$} \\
\hline & GrN- 18.230 & & $\begin{array}{l}930-750 \\
710-530 \\
\end{array}$ & $1060-400$ & \multicolumn{2}{|c|}{$670 \pm 130$} \\
\hline \multirow{12}{*}{$\begin{array}{l}\text { 6. Cabezo de } \\
\text { Ballesteros }\end{array}$} & CSIC 607 & $2390 \pm 50$ & & & \multicolumn{2}{|c|}{-} \\
\hline & & & \multicolumn{2}{|c|}{ - } & \multirow{2}{*}{\multicolumn{2}{|c|}{ - }} \\
\hline & $\begin{array}{l}\text { CSIC } 608 \\
\text { Gr. } 13.343\end{array}$ & $\begin{array}{l}2410 \pm 50 \\
2490 \pm 30\end{array}$ & \multicolumn{2}{|c|}{ - } & & - \\
\hline & Gr. 13.344 & $2560 \pm 30$ & \multicolumn{2}{|c|}{ - } & \multicolumn{2}{|c|}{ - } \\
\hline & Gr. 13.345 & $2480 \pm 40$ & \multicolumn{2}{|c|}{-} & \multicolumn{2}{|c|}{ - } \\
\hline & Gr. 13.346 & $2510 \pm 35$ & \multicolumn{2}{|c|}{-} & \multicolumn{2}{|c|}{ - } \\
\hline & Gr. 13.347 & $2330 \pm 50$ & \multicolumn{2}{|c|}{-} & \multicolumn{2}{|c|}{-} \\
\hline & Gr. 13.352 & $2500 \pm 50$ & \multicolumn{2}{|c|}{-} & \multicolumn{2}{|c|}{ - } \\
\hline & Gr. 13.353 & $2475 \pm 35$ & & & & the \\
\hline & Gr. 13.354 & $2480 \pm 35$ & & & & 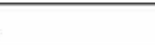 \\
\hline & Gr. 13.355 & $2470 \pm 25$ & & & & 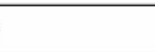 \\
\hline & Gr. 13.346 & $2530 \pm 30$ & & & & 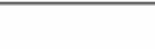 \\
\hline
\end{tabular}

Fig. 6.- Fechas radiocarbónicas de los yacimientos celtibéricos estudiados (1, Vega, 2007. 2, Vega 2002. 3, Arenas, 1999. 4, Chordá, 2008. 5, Collado et al. 1991-1992. 6, Pérez Casas, 1990). 


\begin{tabular}{|c|c|c|c|c|}
\hline Yacimiento & Muestra & $\begin{array}{c}\text { Tipo muestra y } \\
\text { contexto }\end{array}$ & $\begin{array}{c}{\text { Fecha } \mathrm{C}^{14}} \\
\text { convencional }\end{array}$ & $\begin{array}{c}\text { Calibración } \\
2 \text { sigmas } \\
\end{array}$ \\
\hline \multirow[t]{3}{*}{ Herrería I } & GrA-20603 & $\begin{array}{l}\text { Huesos cremados } \\
\text { T-67 }\end{array}$ & $3010+-50 \mathrm{BP}$ & $\begin{array}{c}\text { BC } 1430-112 \\
\text { BP } 3200-2800\end{array}$ \\
\hline & Beta-238145 & $\begin{array}{c}\text { Huesos cremados } \\
\text { T-242 } \\
\end{array}$ & $3010+-40 \mathrm{BP}$ & $\begin{array}{l}\text { BC } 1390-1120 \\
\text { BP } 3340-3070 \\
\end{array}$ \\
\hline & Beta-221267 & $\begin{array}{c}\text { Huesos cremados } \\
\text { T-48 }\end{array}$ & $3000+-50 \mathrm{BP}$ & $\begin{array}{l}\text { BC } 1390-1060 \\
\text { BP } 3340-3000\end{array}$ \\
\hline \multirow[t]{3}{*}{ Herrería II } & GrN-26942 & $\begin{array}{c}\text { Huesos inhumados } \\
\text { T-138 } \\
\end{array}$ & $2820+-40 \mathrm{BP}$ & $\begin{array}{l}\text { BC } 1125-839 \\
\text { BP 2950-2700 }\end{array}$ \\
\hline & Beta-238146 & $\begin{array}{c}\text { Huesos cremados } \\
\text { T-164 } \\
\end{array}$ & $2800+-40 \mathrm{BP}$ & $\begin{array}{l}\text { BC } 1040-840 \\
\text { BP 2990-2790 } \\
\end{array}$ \\
\hline & Beta-230898 & $\begin{array}{c}\text { Huesos cremados } \\
\text { T-79 }\end{array}$ & $2740+-40 \mathrm{BP}$ & $\begin{array}{c}\text { BC } 980-810 \\
\text { BP } 2930-2760\end{array}$ \\
\hline \multirow{2}{*}{ Inchidero I } & Beta-290576 & $\begin{array}{c}\text { Huesos cremados } \\
\text { T-C5T9 }\end{array}$ & $2540 \pm 30 \mathrm{BP}$ & BC 680 \\
\hline & Beta-290577 & $\begin{array}{l}\text { Huesos cremados } \\
\text { T-C3G14T2 }\end{array}$ & $2500 \pm 40 \mathrm{BP}$ & BC 656 \\
\hline \multirow[t]{2}{*}{ Inchidero II } & Beta-290581 & $\begin{array}{l}\text { Huesos cremados } \\
\text { T-C3G13T3 }\end{array}$ & $2380 \pm 40 \mathrm{BP}$ & BC 453 \\
\hline & Beta-2905 & $\begin{array}{l}\text { Huesos cremados } \\
\text { T-C5T5 }\end{array}$ & $2370 \pm 40 \mathrm{BP}$ & BC 451 \\
\hline
\end{tabular}

Fig. 7.- Algunas de las fechas radiocarbónicas obtenidas en las fases del Bronce Final de Herrería I y II (Vega, 2016,183 y Cerdeño y Sagardoy, 2016, 209 y ss) y en las fases de la Primera y Segunda Edad del Hierro de El Inchidero (Arlegui, 2012, 195), que enmarcan hacia atrás y hacia adelante las cronologías obtenidas en los yacimientos estudiados.

\section{El territorio de Celtiberia. Fácil acceso al HIERRO.}

La interpretación de los elementos de hierro que estamos analizando, como en cualquier otro caso, es más completa si se tiene en cuenta el entorno en que aparecieron puesto que puede aportan información no solo adicional. Por el tema que ahora tratamos creemos que es importante recordar la naturaleza geológica del territorio celtibérico, para evaluar la facilidad de acceso al hierro y si hubo relación entre esa disponibilidad de materia prima y la aplicación de la nueva técnica. Es cierto que faltan estudios sobre la minería, así como análisis arqueometalúrgicos de las colecciones de objetos conservados pero eso no impide, más bien al contrario, que haya que fijarse en el paisaje circundante y valorar sus posibilidades de aprovechamiento.
Los límites exactos del territorio histórico de Celtiberia no pueden trazarse con absoluta precisión por motivos obvios y con frecuencia se han comentado en los sucesivos Symposia sobre los celtíberos, hasta que el profesor F. Burillo elaboró, sobre otros anteriores, un mapa que desde entonces sirve de referencia general (Burillo 1998). Si seguimos los criterios restrictivos, el núcleo central abarcaría el sur de Aragón y las tierras altas de la Meseta oriental, es decir, desde el Medio Ebro hasta la cabecera del Duero, incluyendo el Alto Tajo y los valles del Jiloca y Jalón, comarcas que corresponden hoy a las provincias de Zaragoza, Teruel, Guadalajara y Soria y, ampliando esos criterios, podría incluirse la zona norte de Cuenca por el sur y Segovia o La Rioja por el norte y oeste (fig. 1). En definitiva, estaba situada al pie del Sistema Ibérico, 
con tierras ricas en minas de hierro ${ }^{4} \mathrm{y}$ filones de diferente entidad y rentabilidad en todas sus estribaciones, caso del Moncayo o Sierra Menera, donde son un buen ejemplo las famosas de Ojos Negros o las de Setiles, cada una a un lado del límite de las actuales provincias de Teruel y Guadalajara y explotadas hasta bien entrado el siglo XX. Incluso tienen este metal los territorios ya en contacto con el Sistema Central, como el caso de la sierra de Ayllón, donde están los minerales de hierro más importantes de todo el sector oriental de la Meseta Norte (Barrio 2006, 27).

La extracción de estas mineralizaciones de hierro, no rentables en época actual, pudo ser importante en la Edad del Hierro al ser relativamente fácil dado que muchas afloraciones eran superficiales y se accedería a ellas a partir de pequeñas zanjas. El interés que desde antiguo tuvieron estas formaciones metálicas ya fue recalcado por algunos autores hace tiempo (MartínCostea y Ruíz-Zapatero 1980) y específicamente su explotación en época celtibérica parece clara en casos concretos estudiados, como en la zona del Jalón-Mesa donde se observó concentración de asentamientos prerromanos cerca de sitios con recursos mineros de hierro (Martínez-Naranjo 1994, 163) mismo caso que, por ejemplo, el poblado de El Turmielo (Arenas et al. 1995, 182). La metalurgia del hierro también fue objeto de debate en el IV Symposio sobre los celtíberos (Barrio 1999. Lorrio et alii 1999. Martínez-Naranjo y Arenas 1999. Polo 1999) y se han realizado posteriormente algunos estudios específicos (Rovira et alii 2002. Polo y Villagordo 2003).

La explotación moderna de muchos de estos filones férricos y su anterior explotación en época romana han borrado las huellas que pudieran quedar de actividad previa en las propias minas $\mathrm{y}$, en cualquier caso, es difícil encontrar vestigios de sencillos talleres metalúrgicos asociados a los poblados, puesto que estarían ubicados fuera del recinto habitacional y las labores agrícolas los habrán destruido en un gran número de casos. Ni siquiera resulta fácil localizar los filones ni los talleres y herrerías de los siglos XVI-XIX (Gimeno y Martín 2002-03). Por ello nos parece interesante el proyecto sobre la minería y siderurgia antiguas en Sierra Menera (Fabre et alii 2012) porque trabajos como este permitirán un mejor acercamiento a las técnicas metalúrgicas, de extracción y transformación, con las que se fabricaron los objetos que si conocemos bien. Dicho estudio ha permitido localizar posibles centros de trasformación del mineral, a partir de escoriales asociados a enclaves de la Edad del Hierro (Ibidem, 48), aunque es cierto que los lugares estudiados se fechan entre los siglos II a. C y II d. C., muy ale- jados de la época que aquí estudiamos. Sin embargo, nos parece interesante la metodología aplicada y el modelo detectado de pequeños enclaves rurales dispersas por el territorio, que en un $50 \%$ de los casos estaban asociados a escoriales y que los autores consideran indicativo de la realización de actividades metalúrgicas en el propio entorno (Ibidem, 55). Ese modelo de poblamiento es el que se identifica desde los inicios de la Edad del Hierro, por ejemplo La Coronilla, El Ceremeño, El Palomar, Turmielo, Griegos, etc., es decir, pequeños castros con estructura interna bien definida que con frecuencia no alcanzan una hectárea, separados entre sí pocos kilómetros y que aprovechaban los recursos disponibles en su entrono, incluyéndolos en su sistema socio-económico, en una auténtica red de castros con un buen entramado de relaciones y alianzas (Ortega 1999, 115), que seguramente garantizó su éxito y perdurabilidad.

Naturalmente que esa perdurabilidad del modelo poblacional no implica que las actividades económicas fueran las mismas desde el principio, pero sería factible si tenemos en cuenta la disponibilidad de materia prima y la relativa abundancia de objetos férricos encontrados. El debate podría centrarse en si se trata de piezas fabricadas localmente o si fueron elementos de importación, pero la mayoría de los tipos identificados y el número en que aparecen permite pensar que la nueva tecnología de trasformación se adoptó fácilmente y existieron pequeños centros distribuidos por el territorio. Esta propuesta se ha formulado también en otras zonas interiores como las comarcas del Bajo Segre, donde se han localizado abundantes concentraciones de óxido de hierro y se han realizado análisis de algunos materiales fechados en el siglo VII a. C. que han permitido concluir que se trata de producciones locales fabricados con minerales de la zona (Vázquez et alii 2005, 143).

Como han propuesto algunos investigadores, la infraestructura no tendría que ser muy compleja pues son suficientes hornos pequeños en los que se fundiría el mineral sólido, formando una especie de torta con mineral de hierro y algunas impurezas que habría que calentar en otro horno de reducción y, mediante martilleado, eliminar los restos de escoria moldeando un lingote muy quebradizo. Posteriormente, el lingote se recalentaría en la fragua con carbón vegetal que aumentaría su dureza, aunque todavía insuficiente para fabricar determinadas piezas (Polo y Villagordo 2003, 83-85). También puede servir de ejemplo el más tardío yacimiento de Plaza de Moros, fechado en el siglo IV a. C. y ubicado en la Serranía de Cuenca, puesto que allí se han realizado análisis metalográficos sobre

4 Ver los Mapas Geológico, Metalogenético y Minero de las diferentes comarcas 
mineral y sobre subproductos que apuntan a que los pasos que allí se llevaron a cabo eran, igualmente, la tostación, reducción y primera forja para eliminar la escoria y obtener un lingote (Sierra et alii 2002-2003, 370). Si esta tecnología es la que se identifica en las fases más tardías, puede pensarse que en los siglos precedentes sería aún menos elaborada, como indicaron los análisis realizados al fragmento indeterminado de hierro procedente del poblado de las Terraceras I (Ruíz Zapatero y Martín Costea 1984, 30).

\section{Consideraciones FinAles}

En las líneas precedentes hemos descrito los objetos de hierro más antiguos de la Meseta oriental y subrayado las asociaciones más significativas de las que formaban parte, así como algunas fechas absolutas que los enmarcan en la Primera Edad del Hierro, cuyo inicio a fines del siglo VIII a. C. se acepta de forma generalizada en la mayoría de los territorios peninsulares. El caso de la cultura celtibérica resulta interesante porque durante mucho tiempo las fases que mejor se conocían eran las tardías y ha sido en las últimas décadas cuando se han documentado bien las fases iniciales. Ya se dispone de información sobre numerosos aspectos materiales, económicos, sociales o demográficos de comienzos de la Edad del Hierro, algunos de los cuales se remontan al Bronce Final indicando el desarrollo de un proceso cultural de larga duración.

Muchos yacimientos celtibéricos se descubrieron hace más de cien años y no sabríamos decir si eso ha supuesto una ventaja para los estudios actuales. Por un lado ha permitido conocer en detalle las características formales de numerosos objetos, pues aquellos primeros arqueólogos los ordenaron en series tipológicas, algunas muy válidas. Pero, por otro lado, los métodos de la época impidieron a aquellos pioneros detectar diferentes estratos y fases, lo que unido a las manipulaciones posteriores, convirtieron a la mayoría de esos materiales en piezas descontextualizadas. Había que actualizar los antiguos supuestos tipocronológicos, en muchas ocasiones recolocando a la luz de los nuevos datos formas y yacimientos, sacándolos en muchas ocasiones de las casillas en que habían sido incluidos y, para ello, las herramientas metodológicas empleadas han sido la localización de yacimientos nuevos y su excavación sistemática que han permitido confirmar diferentes fases de ocupación sucesivas, asociaciones de materiales y la obtención de fechas radiocarbónicas, todo lo cual permite revisar con mayor solvencia y nueva perspectiva las colecciones antiguas y, de esta manera nuestro conocimiento puede seguir avanzando y no continuar apoyado en argumentos circulares difíciles de romper.

Como es habitual en el trabajo arqueológico, se combinan diferentes variables entre las que tiene gran peso específico la ordenación tipológica de los materiales pero, precisamente porque se acepta el valor diagnóstico de algunos de ellos, puede y debe cambiarse su antigua posición si aparecen estratificados y formando parte de nuevas asociaciones o conjuntos que así lo indiquen. Si además de la seriación relativa se dispone de dataciones absolutas, método mayoritariamente aceptado entre los arqueólogos, se pueden ir fijando con mayor solvencia las secuencian propuestas. No es cierto, como decían los antiguos textos, que las fechas sean la columna vertebral de la Historia pero sí que ayudan a comprender y articular la lógica de los acontecimientos y en el caso de la cultura celtibérica había siglos oscuros que rutinariamente quedaban excluidos del debate aunque, en general, lo que había era épocas mal documentadas que poco a poco se van conociendo mejor.

La mayoría de los objetos metálicos que hemos descrito están bien contextualizados puesto que se encontraron in situ y con buena referencia estratigráfica, muchos en el interior de las tumbas de las necrópolis que, en sí mismas, son conjuntos cerrados muy significativos para corroborar asociaciones y contemporaneidades. Y en esas nuevas asociaciones han aparecido objetos que antes solo se conocían en las colecciones centenarias, de los que no existían estudios detallados y solo se mencionaban siguiendo lo que habían dicho sus descubridores sin mayor discusión. Algunos de estos objetos tuvieron mayor pervivencia pero otros han aparecido exclusivamente en contextos antiguos pues, junto a ellos, se encontraron elementos a los que nadie duda en situar en la Primera Edad del Hierro como son las fíbulas de bronce de codo con pivote, las de bucle, de El Acebuchal o de doble resorte, además de cerámicas a mano bicónicas, morillos prismáticos o cerámicas ibéricas a torno del Ibérico Antiguo. Si estas asociaciones se pueden completar además con fechas absolutas, creemos que se consigue un registro material más sólido que puede hacer variar antiguos supuestos, como ocurre en cualquier disciplina científica.

Otro aspecto que nos parece igual de significativo es la propia tipología de estas primeras piezas fabricadas precisamente en hierro, cuando era una materia prima nueva y aún solo accesible a determinados miembros de la sociedad. Los pequeños cuchillos asociados a fíbulas navarro-aquitanas, a los demás modelos de fíbulas mencionados, a pulseras, brazaletes o arandelas muestran que son piezas mayoritariamente de adorno, seleccionadas como signo de distinción social o de identidad que sus propietarios incluyeron entre sus estandarizados ajuares funerarios. Su distribución geográfica marca vías de contacto con otras regiones, que pueden ser expresión de relaciones entre grupos sociales con ciertas afinidades que, de esta manera, afianzaban su interconexión en momentos en los que todavía necesitarían cohesión y apoyo mutuo. 
En el caso que nos ocupa, la duda que todavía persiste es el lugar en que se fabricaron dichos elementos porque no hay demasiados estudios ni arqueometalúrgicos ni de minería celtibérica que permitan argumentar el tema con solvencia. Con el registro disponible la hipótesis más plausible es que la nueva tecnología del hierro llegó al territorio meseteño desde fuera, al igual que se acepta en el resto de los territorios peninsulares. Diferente es si las piezas que encontramos se fabricaron también en otras regiones o si hubo tempranas producciones locales y es posible que ocurriera esto último ya que las tierras del Sistema Ibérico son ricas en filones de hierro y, como hemos visto, en zonas cercanas del valle del Ebro se está demostrando la existencia de pequeños talleres propios en la Primera Edad del Hierro. La posible fabricación local no implica que se descubriera allí la siderurgia, ni siquiera que todos los modelos producidos se diseñaran también en el mismo lugar pero, en cualquier caso, hablar en profundidad de importaciones, imitaciones o diseños propios excedería los límites de este trabajo y requeriría, además, análisis arqueométricos que solamente acabamos de iniciar.

La conclusión a la que llegamos es que en el estudio de la cultura celtibérica todavía queda bastante camino por recorrer. Durante mucho tiempo fue un territorio poco atractivo para la investigación y por ello aún estamos procesando la abundante información recabada en los últimos años y que, como parece natural, obliga a cambiar algunos presupuestos que se formularon hace casi un siglo, algunos de ellos de gran interés pero que, sin duda, pueden ser matizados.

\section{Bibliografía}

Adroit, S. (2014 e. p.): “Architectes de la mort: un état de la question entre Garonne et Ebre au $\mathrm{I}^{\text {ere }}$ millenaire a. C". En S. Adroit y R. Graells (coords): Arquitecturas funerarias y memoria: la gestión de las necrópolis en Europa occidental (siglos X-III a. C.). Casa de Velazquez-Römisch Germanisches Zentralmuseum. Madrid.

Almagro-Basch, M. (1942): "La necrópolis céltica de Griegos”. Archivo Español de Arqueología, XV, 47: 104-113.

Almagro-Gorbea, M. (1993): La introducción del hierro en la Península Ibérica. Contactos precoloniales en el período Protoorientalizante. Complutum, 4: 81-94.

Álvarez, A. (1990): El Bronce Final y el Hierro Inicial en la región aragonesa. Estado actual de la Arqueología en Aragón, tomo I. Institución Fernando El Católico. Zaragoza.

Álvarez-Sanchís, J. (2000): "The Iron Age in Western Spain (800 BC-AD 500)". Oxford Journal of Archaeology, 19 (1): 65-89. https://doi.org/ 10.1111/1468-0092.00100.
Álvarez-Sanchís, J., Lorrio, A. y Ruíz-Zapatero, G., 2016: "Los primeros elementos de hierro en Iberia". Homenaje a la profesora Concepción Blasco. Anejos CuPAUAM, 2: 149-165.

Aranda, A. (1990): ”Necrópolis celtibéricas en el Bajo Jiloca". En F. Burillo (coord.): II Symposio sobre los celtíberos. Necrópolis celtibéricas. Zaragoza: 101-110.

Arenas, J. A. (1999): La Edad del Hierro en el Sistema Ibérico Central. British Archaeological Reports Internacional Series S780. Oxford

Arenas, J. A. y Cortés, 1. (1995): "Ritos Funerarios en la necrópolis celtibérica de Aragoncillo (Guadalajara, España)". Ritual, ritos y religión. III Conferencia de Deiá. Palma de Mallorca.

Arenas, J. A.; González, M. L. y Martínez-Naranjo, J. P. (1995): "El Turmielo de Aragoncillo (Guadalajara): señales de diversificación funcional del hábitat en el periodo Protoceltibérico". En F. Burillo (coord.): III Symposio sobre los celtíberos. Poblamiento celtibérico. Zaragoza: 179-183.

Argente, J. L. (1994): Las fíbulas de la Edad del Hierro de la Meseta oriental. Valoración tipológica, cronológica y cultural. Excavaciones Arqueológicas en España, 168. Madrid.

Argente, J. L., Díaz, A. y Bescós, A. (2000): Tiermes V. Carratiermes, necrópolis celtibérica. Campañas 1977 y 1986-1991. Arqueología en Castilla y León, 9. Valladolid.

Arlegui, M. (2012): "La necrópolis celtibérica del Inchidero (Aguilar de Montuenga, Soria): estratigrafía, cronotipología y dataciones radiocarbónicas". Complutum, 23 (1): 181-201.

Arlegui, M. (2014): “La necrópolis de El Inchidero, Aguilar de Montuenga, Soria". En F. Burillo y M. Chordá (eds): VII Symposio sobr los celtíberos. Nuevos hallazgos, nuevas interpretaciones. Zaragoza: 379-386.

Aubet, M. E. (1987): Tiro y las colonias fenicias de Occidente. Ediciones Bellaterra. Barcelona.

Baquedano, I., Azcárraga, S. y Martínez-Escorza, C. (2016): "Repensando la necrópolis de incineración de la Primera Edad del Hierro del Arroyo Culebro (Leganés, Madrid)". Homenaje a la profesora Concepción Blasco. Anejos CUPAUAM, 2: 2005217.

Barrio, J. (1999): "La temprana metalurgia del hierro en la Sierra de Ayllón a partir de los elementos férreos de la necrópolis de La Dehesa (Ayllón, Segovia)". En F. Burillo (coord.): III Symposio sobre los Celtíberos. Economía. Zaragoza: 181-194.

Barrio, J. (2006): La necrópolis celtibérica de La Dehesa de Ayllón. Fondos del Museo de Segovia. Estudios y Catálogos, 16. Museo de Segovia. Junta de Castilla y León. Valladolid. 
Blánquez, J. y Rodríguez, B. (eds), (2004): El arqueólogo Juan Cabré (1882-1947). La fotogrfía como técnica monumental. IPH-UAM-Museo San Isidro. Madrid.

Boch Gimpera, P. (1921): "Los celtas y la civilización céltica en la Península Ibérica". Boletín de la Sociedad Española de Excursionistas XXIX: 248-301.

Brun, P. (2002): "El torques en Europa". En M. Barril y A. Rodero (dirs): Torques. Belleza y poder. Museo Arqueológico Nacional. Madrid: 47-58.

Burillo, F. (1998): Los Celtíberos. Etnias y estados. Crítica. Barcelona.

Burillo, F. (coord.), (1999): IV Symposio sobre los Celtíberos. Economía. Institución Fernando El Católico. Zaragoza.

Cabré, J. (1930): Excavaciones arqueológicas en la necrópolis celtibérica de El Altillo del Cerropozo (Atienza, Guadalajara). Junta Superior de Excavaciones y Antigüedades, mem. 105. Madrid.

Cabré, J. (1939-1940): La caetra y el scutum en Hispania durante la Segunda Edad del Hierro. Boletín del Seminario de Arte y Arqueología, 6: 57-83.

Cabré, J. y Cabré M. E. (1933): "Datos para la cronología del puñal de la cultura de Las Cogotas". Archivo Español de Arqueología, 25: 37-45.

Castiella, A. (2005): "Sobre los ajuares de la necrópolis de La Atalaya. Cortes, Navarra". Cuadernos de Arqueología de la Universidad de Navarra, 13: 115-210.

Castiella, A. y Tajadura, J. (2001): “Campos de Urnas en Navarra". Cuadernos de Arqueología de la Universidad de Navarra., 9: 197-222.

Castro, P.; Lull, V. y Micó, R. (1996): Cronología de la Prehistoria Reciente de la Península Ibérica y Baleares (c. 2800-900 cal ANE). British International Series, 652. Oxford

Celestino, S.; Rafel, N.; Armada, X. L. (eds), (2008): Contacto cultural entre el Mediterrámeo y el Atlántico (siglos XII-VIII ane): la precolonización a debate. Escuela Española de Arqueología en Roma, Serie Arqueológica, 14. CSIC. Madrid.

Cerdeño, M ${ }^{\text {a }}$ L.; García-Huerta, R y de Paz, M. (1981): "La necrópolis celtibérica de Molina de Aragón (Chera, Guadalajara). Campos de Urnas en la Meseta oriental". Wad-al-Hayara, 8: 9-84.

Cerdeño, M ${ }^{\mathrm{a}}$ L. y Pérez de Inestrosa, J. L. (1993): La necrópolis de Sigüenza: revisión del conjunto. Monografías Arqueológicas del SAET, 6. Teruel.

Cerdeño, M ${ }^{\mathrm{a}}$ L. y Juez, P. (2002): El castro celtibérico de El Ceremeño (Herrería, Guadalajara). Monografías Arqueológicas del SAET, 8. Zaragoza.
Cerdeño, Ma L. y Chordá, M. 2004: Fíbulas de tipo navarro-aquitano en el área celtibérica. Cuadernos de Arqueología de la Universidad de Navarra, 12: 161-175.

Cerdeño, M ${ }^{\mathrm{a}}$ L. y Sagardoy, T. (2007): La necrópolis celtibérica de Herrería III y IV (Guadalajara). Estudios Celtibéricos, 4. Zaragoza.

Cerdeño, M ${ }^{\mathrm{a}}$ L. y Sagardoy, T. (2016): La necrópolis celtibérica de Herrería I y II. Las fases culturales del Bronce final II-III. La Ergástula. Madrid

Constantin, T. y Chordá, M. (2014): "Las fíbulas navarro-aquitanas y su contextualización a ambos lados de los Pirineos". En F. Burillo y M. Chordá (eds): VII Symposium sonre Los Celtíberos. Nuevos hallazgos. Nuevas interpretaciones. Zaragoza: 223-230.

Collado, O. (1990): El poblamiento en la Sierra de Albarracín. Memorias del S.A.E.T, 6. Teruel.

Collado, O.; Ibañez, R.; Nieto, E. y Cotino, F. (19911992): "Dataciones por radiocarbono de Montón de Tierra, Griegos (Teruel): el C-14 como método de fechación del período Celtibérico Antiguo". Kalathos 11-12: 139-156.

Chordá, M. (2008-2009): “Análisis radiocarbónicos en la necrópolis de Griegos (Teruel)". Revista Teruel: 9-18.

Chordá, M. (2014): "Nuevas interpretaciones en la necrópolis celtibérica de El Cuarto de Griegos (Teruel)". En F. Burillo y M. Chordá (eds): VII Symposium sobre Los Celtíberos. Nuevos hallazgos. Nuevas interpretaciones. Institución Fernando el Católico. Zaragoza: 397-404.

Chordá, M., Collado, O. y Nieto, E. (2013-14): "Las tumbas inéditas de la necrópolis de "El Cuarto" (Griegos, Teruel)". Kalathos, 26-27: 211-237.

Chordá, M. y Pérez-Dios, P. (2014): "La funcionalidad de los objetos arqueológicos: el ejemplo de las supuestas "diademas femeninas". En F. Burillo y M. Chordá (eds): VII Simposio sobre Celtíberos: Nuevas investigaciones, nuevas interpretaciones. Zaragoza: 405-412.

Domínguez, L. (1982): "Los materiales de la necrópolis de Almaluez conservados en el Museo Arqueológico Nacional". Trabajos de Prehistoria, 39: 241-278.

Escudé-Quillet, J-M. (998): Du complexe pyrénéen au complexe sud-aquitain: La fin de l'Âge du Bronze et l'Âge du Fer d'Aquitaine méridionale. Thèse Universitaire. Toulouse le Mirail.

Escudé-Quillet, J-M (2000): «Éléments d'étude sur les practiques funeraires du Bronze Final et du debut de l'Àge du Fer en Aquitaine medirional ». XXI Colloque International de l'AFEAF. Monographies d'Archéologie Mediterranéenne, Escudé-Quillet, J-M 5. Lattes: 131-140. 
Fabre, J-M. ; Polo, C. ; Villagordo, C. y Coustures, MP. (2012): "Minería y siderurgia antigua en Sierra Menera (Teruel-Guadalajara). Nuevos avances de la explotación del hierro en época antigua (siglos II a. C.-II d. C.)". En A. Orejas y Ch. Rico: Minería y metalurgia antiguas. Visiones y revisiones. Homenaje a Claude Domergue. Collection Casa de Velazquez, 128. Madrid: 43-62.

Faro, J. A. y Unzu, M. (2006): “La necrópolis de la Edad del Hierro de El Castillo (Castejón, Navarra). Primeras valoraciones: campañas 2000-2002". Complutum, 17: 145-166.

Fuentes, C. (2004): La necrópolis celtibérica de Viñas de Portuguí (Osma, Soria). Las colecciones Rus y Morenas de tejada en el Museo Arqueológico Nacional. Toxosoutos Ediciones. A Coruña.

García-Soto, E. (1990): “Las necrópolis de la Edad del Hierro en el Alto valle del Duero. II Symposium sobre Los Celtíberos. Necrópolis celtibéricas: 1338. Zaragoza.

Gimeno, E. B. y Martín, F. (2003-04): "Noticias para la elaboración de un mapa del patrimonio metalúrgico preindustrial en la Cordillera Ibérica (15001850)". Kalathos, 22-23: 329-344.

González-Prats, A. (1992): “Una vivienda metalúrgica en la Peña Negra (Crevillente, Alicante). Aportaciones al conocimiento del Bronce Atlántico en la Península Ibérica". Trabajos de Prehistoria, 49: 243-257. https://doi.org/10.3989/tp.1992.v 49.i0.544.

González-Prats, A. ( 2014): La Fonteta 2. Estudio de los materiales arqueológicos hallados en la colonia fenicia de la actual desembocadura del río Segura (Guardamar del Segura, Alicante). Seminarios Internacionales sobre Temas Fenicios. Alicante.

Graells, R. (2010): Las tumbas con importaciones y la recepción del Mediterráneo en el nordeste de la Península Ibérica (siglos VII-VI a.C.). Revista d'Arqueologia de Ponent, Número Extra. Universitat de Lleida.

Jover, F. J.; Lorrio, A. y Díaz-Tena, M. D. (2016): “El Bronce Final en el levante de la Península Ibérica: novedades tipológicas e interpretacions". Complutum, 27 (1): 81-108.

Junyent, E. (1992): "Els orígens del ferro a Catalunya". Revista d'Arqueología de Ponent, 2: 21-35.

López-Cachero, F. J. (2007): “Sociedad y economía durante el Bronce Final y la Primera Edad del Hierro en el Noreste peninsular: aproximación a partir de las evidencias Arqueológicas". Trabajos de Prehistoria, 64 (1): 99-120.

López Cachero, F. J. y Rovira, C. (2012): “El món funerari a la depresió prelitoral catalana entre el
Bonze Final i la primera Edat del Ferro: ritual y dinamisme social a partir del registre arqueològic". En C. Rovira, F. J. López-Cachero y F. Mazière (dirs): Las necrópoli d'incineració entre l'Ebre i el Tiber (segles IX-VI a. C.): metodologia, pràctiques funeraries $i$ societat. Museu d'Arqueologia de Catalunya. Monografies, 14. Barcelona: 37-55.

Lorrio, A. (1994): "La evolución de la panoplia celtibérica". Madrider Mitteilungen, 35: 212-257.

Lorrio, A. (2008): Querénima. El Bronce Final del Sudeste peninsular de la Pnínsula Ibérica. Bibliotheca Archaeologica Hispana, 27. Real Academia de la Historia. Madrid.

Lorrio, A.; Gómez, P., Montero, I. y Rovira, S. (1999): "Minería y metalurgia celtibérica". III Symposio sobre los Celtíberos. Economía. Zaragoza: 161-180.

Lorrio, A. y Sánchez de Prado, M. D. (2009): La necrópolis de Arcóbriga. Caesaraugusta, 80. Zaragoza.

Malpesa, E. (1993): "La "sacerdotisa del sol" y el collar sideral. La tumba 53 de la necrópolis de Clares (Guadalajara)". Boletín del Museo Arqueológico Nacional, XI: 17-44.

Maluquer, J. y Vazquez de Parga, L. (1957): Avance del estudio de la necrópolis de La Atalaya de Cortes de Navarra. Excavaciones en Navarra, V: 121-188.

Mangas, J. y Myro, M. del M. (eds) (2003): Medio físico y recursos naturales de la Península Ibérica en la Antigüedad. Testimonia Hispaniae Antiqua III. Editorial Complutense. Madrid

Martín-Costea, A. y Ruíz-Zapatero, G. (1980): “La metalurgia del hierro en el poblado protohistórico de Vallipón (Teruel)". Revista de Metalurgia, 16 (1): 31-40.

Martínez-Naranjo, J. P. (1997): "El inicio del mundo celtibérico en el interfluvio Alto Jalón-Mesa". Complutum, 8: 161-182.

Martínez-Naranjo, J. P. y Arenas, J. (1999): “La explotación de hierro en el curso alto del río Mesa (Guadalajara) en época celtibérica". En F. Burillo (coord.): III Symposio sobre los Celtíberos. Economía. Zaragoza: 203-207.

Martínez-Naranjo, J. P y de la Torre (2014): “Castil de Griegos y Puente de la Sierra: un modelo de poblamiento celtibérico en el Alto Tajo". En F. Burillo y M. Chordá (eds): VII Simposio sobre Celtíberos. Nuevas investigaciones, nuevas interpretaciones. Zaragoza: 57-63.

Mederos, A. (2008): "El Bronce Final". En F. Gracia (coord.): De Iberia a Hispania. Ariel. Barcelona: 19-91.

Mohen, J-P. (1974): « Les fibules de l’Age du Fer aquitain ». Revue Historique et Archéologique du Libournais, XLII, 152 : 78-88. 
Mohen, J-P. (1980): L’Âge du Fer en Aquitaine. Memoires de la Société Préhistorique Française, 14. Paris.

Ortega, J. M. (1999): “Al margen de la "identidad cultural": historia social y económica de las comunidades campesinas celtibéricas". En F. Burilllo (coord.): IV Symposio sobre los celtíberos. Economía. Zaragoza: 127-144.

Paz, M. de (1980): "La necrópolis céltica de El Atance (Guadalajara)". Wad-Al-Hayara, 7: 35-57. Guadalajara.

Peña, A. de la (1992): El castro de Torroso (Mons, Pontevedra). Síntesis de las memorias de las campañas de excavaciones 1984-1990. ArqueoloxiaMemorias 11. Xunta de Galixcia. A Coruña.

Pérez-Casas, J. A. (1984): Datación Radiocarbónica de la necrópolis de incineración del Cabezo de Ballesteros. Boletín del Museo de Zaragoza: 113-124.

Pérez-Casas, J. A. (1990):" Las necrópolis de incineración del Bajo Jalón". En F. Burillo (coord.): II Symposium sobre Los Celtíberos. Necrópolis Celtibéricas. Zaragoza: 111-121.

Polo, C. (1999): “La metalurgia del hierro durante la época celtibérica en Sierra Menera (GuadalajaraTeruel)". En F. Burillo (coord.): IV Symposio sobre los Celtíberos. Economía. Zaragoza: 195-2001.

Polo, C. y Villagordo, C. (2003): “Los celtíberos: los poblados fortificados y la explotación del hierro en Sierra Menera". En E. B. Gimeno (ed.): Comarca del Jiloca. Gobierno de Aragón. Zaragoza: 78-88.

Pons, E. (1986-87): "El principio de la metalurgia del hierro en Catalunya". Zephyrus XXXIX-XL: 251263.

Pons, E. (2003): “De l'edat del bronze a l'edat del ferro a Catalunya: desplaçaments, estades i canvi cultural". Cota Zero, 18: 106-130.

Quesada, F. (1991): El armamento ibérico. Tesis Doctoral. Universidad Autónoma de Madrid.

Quesada, F. (1997): El armamento ibérico. Estudio tipológico, geográfico, funcional, social y simbólico de las armas en la cultura ibérica (siglos VI-I a. $C)$. Monique Mergoil. Montagnac.

Rafel, N. (1991): La nècropolis del Coll del Moro de Gandesa. Els materials. Publicaciones de la Diputació de Tarragona. Tarragona.

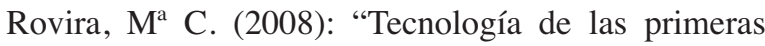
manufacturas férricas en el noreste de la Península Ibérica". En S. Rovira; M. García-Heras; M. Gener i I. Montero (eds.): VII Congreso Ibérico de Arqueometría: 458-467.

Rovira, S.; Montero, I. y Gómez, P. (2002): "Metalurgia celtibérica en el poblado de El Ceremeño (Guadalajara)”. En M. L. Cerdeño y P.
Juez: El castro celtibérico de El Ceremeño (Herrería, Guadalajara). Memorias del SAET, 8. Teruel: 169-177.

Ruiz-Gálvez, M. (1993): "El occidente de la Península Ibérica, punto de encuentro entre el Mediterráneo y el Atlántico a finales de la Edad del Bronce". Complutum, 4: 41-68.

Ruiz-Gálvez, M. (ed) (1995): Ritos de Paso y Puntos de Paso. La Ría de Huelva en el mundo del Bronce Final europeo. Complutum Extra, 5. Madrid.

Ruiz-Gálvez, M. (2012): Con el fenicio en los talones. Los inicios de la Edad del Hierro en la cuenca del Mediterráneo. Bellaterra. Barcelona.

Ruiz-Zapatero, G. (1992): “Comercio protohistórico e innovación tecnológica: la difusión de la metalurgia del hierro y el torno del alfarero en el NE de Iberia”. Gala, 1: 103-116.

Ruiz-Zapatero, G. (2007): “Antes del Hierro. Cultura y sociedad en el centro de la Meseta (ca. 1200-500 a. C.)". En A. Dávila (ed): Estudios sobre la Edad del Hierro en Carpetania. Zona Arqueológica, 10-I: 36-62.

Ruiz-Zapatero, G. y Martín-Costea, A. (1984): “Las Terraceras I (Mas de Matas, Teruel): un yacimiento de la Primera Edad del Hierro". Kalathos, 2: 7-31.

Sierra, M.; Gómez, J. Mª ; Navarro, J. L.; Baldonedo, J. L. y Soria, A. (2002): “Aproximación a la metalurgia del hierro en la sierra del Monje. Una forma de vida". Bolskan, 19: 369-376.

Sousa, E. de (2016): “A Idade do Ferro em Lisboa: Uma primeira aproximaçao a un faseamento cronológico e à evoluçao da cultura material". CUPAUAM, Cuadernos de Prehistoria y Arqueología de la Universidad Autónoma de Madrid 42: 167-185. https://doi.org/10.15366/ cupauam2016.42.006.

Taracena, B. (1941): Carta Arqueológica de la provincia de Soria. Madrid.

Torres, M. (2002): Tartessos. Bibliotheca Archaeologica Hispana, 14. Real Academia de la Historia. Madrid.

Torres, M. (2017): "El paisaje funerario de las necrópolis tartésicas". En S. Androit y R. Graells: Arquitecturas funerarias y memoria: la gestión de las necrópolis en Europa occidental (ss. X-III a. C.). Ossana Edizione. Venosa.

Vázquez, Mª P.; González, J. R.; Medina, J.; MataPerelló, J. M . y Rodríguez, J. I. (2005): "Actividades siderúrgicas en yacimientos de la Primera Edad del Hierro próximos a la confluencia de los ríos Cinca, Segre y Ebro”. En O. Puche y M. Ayarzagüena (eds): Minería y metalurgía históricas en el Sudoeste europeo. Sociedad Española Defensa Patrimonio Geológico y Minero-Sociedad Española de Historia de la Arqueología. Madrid: 129-145. 
Vega, G. (2002): "Dataciones radiométricas en el castro de El Ceremeño". En M. L. Cerdeño y P. Juez: El castro celtibérico de El Ceremeño (Herrería, Guadalajara). Monografía Arqueológicas del SAET, 8. Zaragoza: 127-131.

Vega, G. (2007): "Dataciones radiocarbónicas de la fase III de la necrópolis de Herrería (Guadalajara)". En M. L. Cerdeño y T. Sagardoy: La necrópolis celtibérica de Herrería III y IV (Guadalajara). Estudios Celtibéricos, 4. Zaragoza: 183-186.
Vilaça, R. (2006): "Artefactos de ferro em contextos do Bronze Final do territorio português: novos contributos e reavaliaçâo dos dados". Complutum, 17: 81-101.

Zamora, T. (2015): Los cuchillos de hierro procedentes de las necrópolis de incineración catalanas (VIIIVI a. C). Clasificación, funcionalidad y tecnología. El caso de Can Piteu-Can Roqueta. Trabajo Fin de Grado. Universidad de Barcelona. [http://diposit. ub.edu]. 
